\title{
A need analysis of technical writing skill of engineering students in India
}

\author{
JCK.Evangeline ${ }^{1 \mathrm{a}}$ and K. Ganesh ${ }^{2}$ \\ ${ }^{1} \mathrm{PhD}$ Research Scholar, Department of English, Sathyabama University Chennai, India \\ ${ }^{2}$ Associate Professor, Department of English, Madras Christian College Chennai, India
}

\begin{abstract}
The development of Science and Technology has bolstered the use of English Language around the world. The purpose of teaching English to non-native speakers of English is to help them in communicating, and more precisely sharing knowledge and information with speakers of other languages. In the field of higher education, the learners need English for Academic purposes (EAP) and learn to use it later for occupational purposes (EOP). Students who had their primary education in English, manage to cope up with this way of the world; whereas students from sub-standard schools or vernacular medium of instruction, many times find it very difficult to cope up with the trend. This paper analyses the need to teach technical writing as a course to students of technical education in order to make them competent in academics and later in their work place. A few sample technical writing papers have been assessed and added to substantiate the need for educating students in technical writing skill. A review of literature and available ESP courses have been done to analyse the present strategies in teaching writing. A course was designed and tried to improve technical writing skill of students of higher education.
\end{abstract}

\section{Introduction}

English has been used as an official language in many a countries. In India, be it in offices, companies or in educational institutions, the use of English is commonly seen. As a result, a teacher of technical education is facing the challenge of equipping the students from various background with the proficiency expected in the corporates. In a non-native English speaking country like India, especially in the last two decades, we find a mushroom growth of English medium schools. In most of these schools, instead of English being taught as a second language, examinations are conducted in English. In other words, students are only assessed through the medium of English. Apart from this, there are also students who have had their education in their vernacular medium. These students require a set of competencies in improving their technical writing skill, which is the most needed, when

\footnotetext{
${ }^{\text {a }}$ Corresponding author: evangeline.jck@gmail.com
} 
they step into multinational companies, for their career. This research is an attempt made to prepare a course on technical writing to better address the specific needs of students of higher education, who have had the above said background. A few factors were considered before collecting the data such as the number of participants to be contacted, the place and time of contact and their medium of study. A set of 150 students participated in the analysis, for collection of data.

\section{Background to the Study}

It is always a concern that that the young scientists and engineers should be taught to write well; and Robert Barrass in his preface to "Scientists must write" says that the scientists and engineers must be able to write good English if they are to be effective as scientists and engineers. These days, the students of Engineering are taught English as one of the subjects and not as a language. Their English syllabi generally include: grammar exercises, listening, writing and reading comprehension. A few universities or colleges add speech practice, communication and other tasks, under Laboratory condition. The method of teaching and learning language remain the same for decades, in spite of all the technological developments. Though educational institutions, especially the technical institutions, claim to have made a paradigm shift in pedagogy, the two papers offered for under-graduate students of Engineering colleges affiliated to Anna University and a few other technical universities, titled as 'Professional Communication', or 'Technical communication' are more English communication and grammar classes rather than technical writing sessions. Amutha Kannan, in one of the famous dailies The Hindu writes that these do not train the prospective engineers to write good projects, documents or proposals (2013). On the contrary, the given course has been built on the student-centered approach, with guided learning. This research is based on the need analysis, as it would help the researcher to define the program goals. A Casper says, a needs analysis can be very formal, extensive and time consuming, but the information gleaned from a needs analysis can be used to help you define program goals [3].

\section{Research Methods Followed}

To analyse the need, responses from the participants were collected through questionnaire. After the analysis, students were asked to write a short article on a technical topic of their choice. This was used as a diagnostic test, for determining what specifically needs to be learned by the trainees. All the trainees took the test and their writing was checked. Once the need was analysed, based on the piece of technical writing by the trainees, it was considered that developing certain skills would help the trainees in achieving the desired result. The report on the analysis is discussed below. The results and responses collected from the student participants aided in evolving the research conclusion. The action plan was arrived in three ways. Skills needed by the students were listed. The purpose of including various topics in the course has been substantiated with samples of the technical writing done by the participants. A review of available courses/programs for Engineering English was undertaken; and finally a course with the needed skills was designed and tested.

\section{Questionnaire for Need Analysis}

A questionnaire with ten questions including objective and open-ended questions, was given to the trainees to find out their personal details, their perception of their own needs and their attitude towards their problem encountered with regard to their language proficiency. The trainees fell under almost similar age group, but varied in their learning 
ability and proficiency in general English. The trainees were final year under-graduate students, young men and women in the age group of 21-26 years; and a few of them had a few years of working experience as well. The trainees were from all over India, and contributed to the study as representatives from different states with different culture and background. All of them knew more than one language. English was used as the communicative language inside the classroom.

\section{Technical Writing - Testing, Analysis and Inference}

\subsection{Reading technical and non-technical texts}

The first step to writing is brainstorming. To brain storm for ideas, students must have had exposure to similar ideas, which is generally acquired by reading or listening to technical and non-technical matters. In the recent past, habit of reading has declined considerably. In a class of 60 , only $10 \%$ of the students have the habit of reading - be it newspaper or books. Students consider reading to be a waste of time, as today's media highlight only politics, crime and cinema. As electronic media gives any information in a tabloid form, students prefer that rather than spending hours on newspapers. Due to this lack of reading habit, the trainees were found to be lost for ideas and concepts to write. The recent survey on the newspaper readership also supports this argument. The average readership has declined considerably during the past ten years. The maximum number of newspaper readers fall under the age group of $65+$.
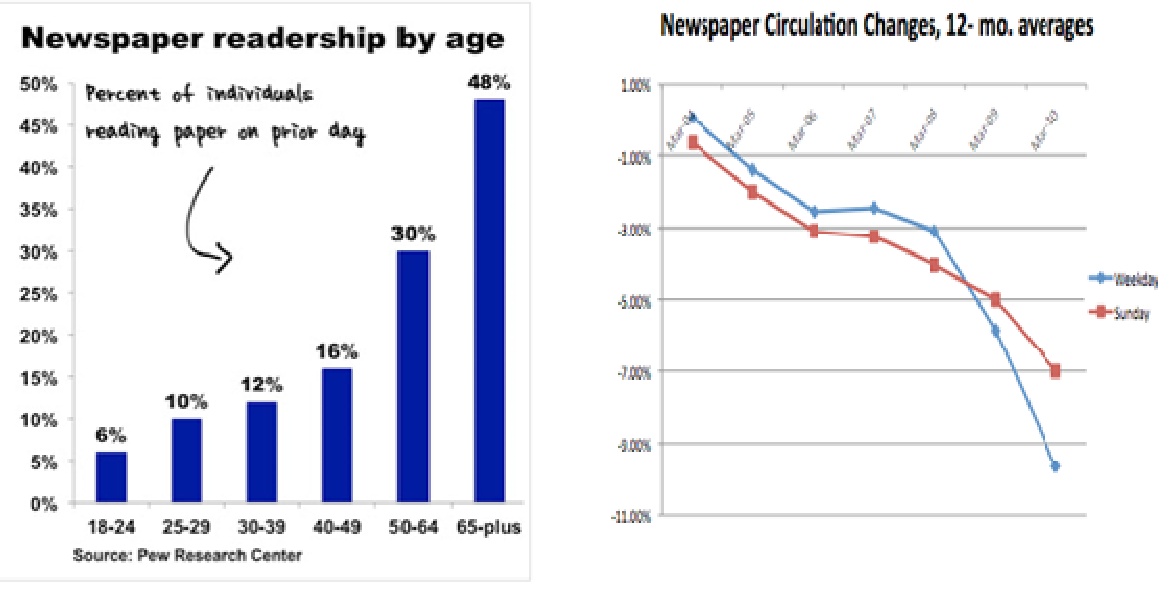

Fig. 1. a. Newspaper readership by age, b. decline of newspaper readership

\subsection{Vocabulary building - Technical}

\footnotetext{
concrete matrix when keplaced in by different proportion of MK and RM, the workability degreased-decreascd with increasing quantity of MK and RM. This happened beeause is duc to the increase of the quantum of fine material in the concrete mix inereased and. As a result. it became difficult to have the same level of good workability even by using superplasticizer The increased in the percentage of replacement of $\mathrm{MK}$ and RM results in more paste volume, which also contributes to a reduction in bleeding. The concrete behaved in a cohesive and mobile mannch during the compacting factor and Xsc-Bec degree tests. It is to be noted peinted out that all the mixtures used in this work exhibited silumps less than $50 \mathrm{~mm}$ which is
}

Fig. 2. Sample 1 of Technical Writing 
It was found that apart from grammatical errors, the major constraint that the trainees faced was lack of vocabulary to present their ideas. This problem creates lot of anxiety while writing. Many do not understand the difference between words like 'essay \& report' or 'remind \& remember' Yet another problem noted was 'malapropism', the use of differently spelt and meant words. When Sripada [6] comments on the issue, she says, in India while framing the syllabi in English for Science and Technology context, collocations are often given little priority. There is more focus on teaching grammar at the tertiary level but not for vocabulary teaching. It is very important for the engineers to use the right word at the right time. As Lewis [7] says, one of the reasons for the success of the executives and outstanding men and women in different fields is their ability to grasp the thoughts of others and convey their thinking and convince the listeners with apt words.

\title{
5.3 Use of passive voice
}

\begin{abstract}
image from the stored data set, based on the users' query. Wened ungent attention in the field of video indexing and image retrieval is the need of the hour. Here-we preppsed a new matrix based indexing technique for image retrieval has been proposed. The proposed method provide better result, experimental results prove this.
\end{abstract}

Fig. 3. Sample 2 of Technical Writing

The technical reports are generally written in passive voice and in impersonal tone. No personal identifiers are used while writing reports, though at times it may create confusion in understanding who does what. Active voice is considered to be "bad writing style in Technical Reports" [8] Active voice may be made use of, for non-technical matters. Some have the tendency to jump between the two. Students need to be taught to follow the same voice throughout the piece of writing. The knowledge of impersonal passive voice is essential, when the students have to write reports.

\subsection{Syntax and Use of appropriate cohesive devices}

\author{
Data mining is the- a process of detecting knowledge from a given \\ huge set of data. Of this the available huge data set, multimedia is the data \\ one which contains diverse data such as Audio, Video, Image, Text and \\ Motion: and -This-grows-the-field-of -video-data-mining-and-the video data
}

been made to identify the hidden infestations, buthlowerer, only a few victorious methods have howeverer, emerged. In this present research work, an attempt is has been made to detect the presence of the pest by

Fig. 4. Samples 3,4 of Technical Writing.a. Syntax, b. Cohesive devices

Appropriate sentence structure Grammar and use of appropriate cohesive devices are very critical for better communication. $37 \%$ of students still showed difficulty while writing, however, they have learnt these as part of their first year Engineering curriculum.

\subsection{Format and style of writing professional/technical reports}

If one has to write on any technical subject, he needs to be aware of the format and style of writing reports and presentations. He should also be conscious of the characteristics of 
technical writing. Among the participants only $30 \%$ were familiar with some of the technical expressions. So it was crucial to teach them how technical writing, is different from other types of writing; and how the information must be presented in a clear and crisp manner, sticking to the point. Another important reason may be having inhibitions in expressing oneself. In a personal Interview, Benjamin Paul, a senior psychologist, who works with corporate employees says that, most of our Engineers are very competent but shy in expressing/communicating their knowledge in words. Maximum number of engineers are into coding and reporting - on average compared to engineers from other countries. The skill of communicating, especially writing is very much needed for these engineers.

\title{
5.6 Transcoding
}

Interpreting the graphs, tables and pictures into a paragraph or Summarizing a paragraph is called transcoding. Only $48 \%$ of the students could to do this, though this is learnt by the Engineering students during the first semester.

\subsection{Introduction to technical expressions and phrasal verbs}

\author{
Hence this work, along with the proposed Clustering techniques, throws eut \\ light on a new matrix based indexing technique for image retrieval. This
}

Fig. 5. Sample 5 of Technical Writing.

Only $30 \%$ of the students could use phrasal verbs and the other technical expressions in appropriate places. The rest of them either made a wrong usage or managed to write without using any technical term at all.

\subsection{Knowledge of Style sheets}

For writing a technical subject matter, students need to learn the acceptable method of writing. There are many styles followed by different universities and organisations. The barest minimum of $8 \%$ of students had knowledge on different style sheets. It is very important fot them to learn as they have projects and reports to write.

\subsection{Use of computes}

Writing today is pervasively and generally digital: composed with digital tools; created out of word, image, sound, and motion; circulated in digital environments; and consumed across a wide range of digital platforms says DeVoss and others [9]. Being born in the age of social networking, most of the students were found to be using computer for social networking. Talking about writing on a personal computer and the basic features available under office was known to only $21 \%$ of the students, though a few others were aware of the features available, they had never taken any time in learning it. It is a territory that they are yet to venture to explore. The world today requires teachers to teach these skills and dispositions students would need for the digital age. Teaching writing along with the skill of using word processing and the other tools in checking the accuracy is very essential. 


\section{Comparison - available courses}

While analyzing the different courses available in colleges and universities it was noted that, in most of the technical institutions, only general writing along with basic grammar is being focused. Evangeline's comparison of syllabi of universities across south India, shows that in technical universities more importance is given to teaching of grammar topics than to writing skill [10]. Almost no university has exclusive paper on 'Technical Writing', included in the engineering curriculum. On the other hand, most of the universities in the western countries, make it mandatory for the students to take up one of the writing courses like creative writing, business writing or technical writing, depending on the course of their choice.

\section{ESP Course Design}

According to Jim Scrivener [11], the syllabus should be designed with activities that promote memory, noticing, reflection and preparation. Added to that, he hopes authentic Exposure along with clarification will result in authentic output. Therefore, the syllabus has been designed making sure of the following details. i) using the learners' existing competence in developing the new skills, ii) analysis of learners' needs in terms of both grammatical and communicative competencies, iii) developing a skill based syllabus based on the needs of the learners, iv) designing a course based on Content and Language integrated learning (CLIL) methodology, to give better exposure to language backing the curriculum and v) use of authentic and genre specific material while planning the course, to make it goal-oriented.

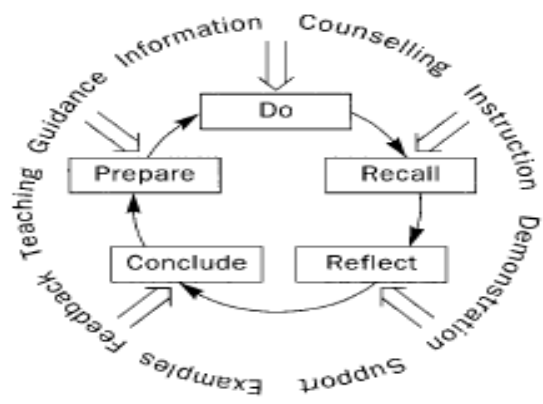

A course has been prescribed based on the study, with a careful eye on the method, using authentic published material, to improve the students' writing skill. The course includes material relevant to academic and occupational purposes, as the participants are soon to go to the industry. Moreover this has been designed to be flexible and open-ended. In the beginning of the program, audio visual and demonstration methods were used. Though it made the learners a bit passive, it enabled them to learn the basics and nuances of technical writing. Whereas the second half of the material was task-based, and demanded more participation. Activities were conducted, to ensure the class participation in the learning process. Peer teaching and supporting was encouraged for maximum retention of learning. Most of the evaluation was done in pairs. A series of tasks were given as assignments along with the criteria of evaluation. A few self-learning modules were also given at the end to help the learner out of the class too. 


\section{Conclusion}

This course was built for post-graduate students. The trainees' needs were studied through standardized tools. These learners are technically sound but unfortunately have limited English language competency to cope up with the program within the short duration. This lack of English proficiency has terrified them, that they couldn't have a positive approach towards the main course. It required a few counselling sessions to get them ready for the class. Though the material used helped them to improve various skills, the main focus was more on the mechanics of writing, the appropriate structure and accuracy. Undertaking more of reading tasks, assignments and presentations will help them in improving their technical writing skill. The effectiveness of the course was evaluated based on oral feedback, and questionnaires after the course. $80 \%$ of the students wanted this course to be incorporated in their curriculum, as an ESP course, as it is more relevant for their immediate needs.

\section{References}

1. Barrass, Robert, Scientists Must Write-A Guide to Better Writing for Scientists, Engineers and Students. London: Routledge, (2005)

2. Kannan, Amutha, Technical writing fails to impress as a career Retrieved from The Hindu: http://www.thehindu.com/todays-paper/tp-national/tp-tamilnadu/technicalwriting-fails-to-impress-as-a-career/article4363534.ece, (2013)

3. Casper, Amie N. "Needs Analysis." TESOL - Volunteers \& Service Learning. online. 15 January 2015, (2003)

4. Reflections of a Newsosaur, Retrieved from Newsosaur Blogspot: http://newsosaur.blogspot.in/2013/01/newspaper-audience-aged-severely-since.html, (2013, January 15)

5. Langeveld, M, Moderating declines: Parsing the NAA's spin on newspaper circ data. Retrieved from Nieman: http://www.niemanlab.org/2010/05/moderating-declinesparsing-the-naas-spin-on-newspaper-circ-data/, (2010, May 4)

6. Sripada, Pushpa Nagini, Teaching Collocations through Placement Training Materials: A Trainer's Perspectives. The International Journal of Humanities Education Volume 12, (C) Common Ground, p11-23, (2015)

7. Lewis Norman, Speak Better Write Better English. Delhi: Goyal Publishers, (2002)

8. Hering Lutz, Heike Hering, How to Write Technical Reports - Understandable Structure, Good Design, Convincing Presentation. Springer: New York, (2010)

9. DeVoss, D`anielle Nicole, Elyse Eidman-Aadahl, and Troy Hicks, Because Digital Writing Matters: Improvising Student Writing in Online and Multimedia Environmens. Jossey Bass: CA, (2010)

10. Evangeline, JCK and Ganesh.K, "Technical Writing - Redefining the English syllabus to meet the Growing Demand for competent Engineers", IOSR Journal Of Humanities And Social Science, Volume 19, Issue 3, Ver. III, PP 27-31, (2014)

11. Scrivener, Jim. Learning Teaching: A Guidebook for English Language Teachers, Ed.2, London: Macmillan, (2005) 